\title{
(2) OPEN ACCESS augmented model of The Productive Ward: Releasing Time to Care on staff and patient outcomes: a naturalistic stepped-wedge trial
}

\author{
Brian Williams, ${ }^{1}$ Carina Hibberd ${ }^{2}$ Deborah Baldie, ${ }^{3}$ Edward A S Duncan, ${ }^{4}$ \\ Andrew Elders (D) , ${ }^{5}$ Margaret Maxwell, ${ }^{4}$ Janice E Rattray, ${ }^{6}$ Julie Cowie, ${ }^{5}$ \\ Heather Strachan (D) , ${ }^{4}$ Martyn C Jones ${ }^{6}$
}

- Additional material is published online only. To view please visit the journal online (http://dx.doi.org/10.1136/ bmjqs-2019-009821).

For numbered affiliations see end of article.

\section{Correspondence to}

Dr Heather Strachan, NMAHP Research Unit, University of Stirling, Stirling FK9 4LA, UK; heather.strachan@stir.ac.uk

An early version of this work was presented at the Royal College of Nursing Research Conference.

Received 20 May 2019 Revised 20 November 2019 Accepted 27 February 2020 Published Online First 26 March 2020

\section{(D) Check for updates}

(C) Author(s) (or their employer(s)) 2021. Re-use permitted under CC BY-NC. No commercial re-use. See rights and permissions. Published by BMJ.

To cite: Williams $B$, Hibberd C, Baldie D, et al. BMJ Qual Saf 2021;30:27-37.

\begin{abstract}
Background Improving the quality and efficiency of healthcare is an international priority. A range of complex ward based quality initiatives have been developed over recent years, perhaps the most influential programme has been Productive Ward: Releasing Time to Care. The programme aims to improve work processes and team efficiency with the aim of 'releasing time', which would be used to increase time with patients ultimately improving patient care, although this does not form a specific part of the programme. This study aimed to address this and evaluate the impact using recent methodological advances in complex intervention evaluation design.

Method The objective of this study was to assess the impact of an augmented version of The Productive Ward: Releasing Time to Care on staff and patient outcomes. The design was a naturalistic stepped-wedge trial. The setting included fifteen wards in two acute hospitals in a Scottish health board region. The intervention was the Productive Ward: Releasing Time to Care augmented with practice development transformational change methods that focused on staff caring behaviours, teamwork and patient feedback. The primary outcomes included nurses' shared philosophy of care, nurse emotional exhaustion, and patient experience of nurse communication. Secondary outcomes covered additional key dimensions of staff and patient experience and outcomes and frequency of emergency admissions for same diagnosis within 6 months of discharge.

Results We recruited 691 patients, 177 nurses and 14 senior charge nurses. We found statistically significant improvements in two of the study's three primary outcomes: patients' experiences of nurse communication (Effect size $=0.15,95 \% \mathrm{Cl}^{\prime} 0.05$ to 0.24 ), and nurses' shared philosophy of care (Effect size $=0.42,95 \% \mathrm{Cl}$; 0.14 to 0.70 ). There were also significant improvements in secondary outcomes: patients' overall rating of ward quality; nurses' positive affect; and items relating to nursing team climate. We found no change in frequency of emergency admissions within six months of discharge. Conclusions We found evidence that the augmented version of The Productive Ward: Releasing Time to Care Intervention was successful in improving a number of
\end{abstract}

dimensions of nurse experience and ward culture, in addition to improved patient experience and evaluations of the quality of care received. Despite these positive summary findings across all wards, intervention implementation appeared to vary between wards. By addressing the contextual factors, which may influence these variations, and tailoring some elements of the intervention, it is likely that greater improvements could be achieved.

Trial registration number UKCRN 14195.

\section{INTRODUCTION}

Definitions of quality have been refined over the past three decades. ${ }^{1}{ }^{2}$ While mortality and clinical outcomes have remained important throughout, other issues such as patient safety, experience, accessibility, equity, efficiency and involvement in decision-making have grown in standing. ${ }^{3}$ Furthermore, there has been a growing empirical basis to support the interconnectedness of these issues. ${ }^{4}$ Wards are, after all, highly complex care environments. ${ }^{5}$

Addressing problems within such complex environments highlights several considerations: complex problems tend to require complex solutions; the more complex a solution is, the more likely its feasibility and effectiveness will vary across sites ${ }^{6}$; and evaluation of the impact of complex solutions is methodologically challenging. Simultaneously maintaining the internal rigour of a study and its applicability to the 'real world' is notoriously difficult. ${ }^{7}$ The ward is an ever-changing environment, embedded within an organisation which itself tends to shift as staff, policies and initiatives change. To assess 
the impact of a complex quality initiative against such a backdrop, and be confident that any improvement in outcomes identified can be attributed to the intervention, is difficult. Yet, such interventions are costly in terms of finance and staff time and energy, therefore requiring a strong evidence base to justify their implementation.

A range of complex ward-based quality initiatives have been developed over recent years. Perhaps the most influential programme has been 'The Productive Ward: Releasing Time to Care' (TPW:RTC). ${ }^{8}$ Designed in conjunction with nurses, TPW:RTC draws on 'Lean methodology'. It focuses on streamlining ward processes, improving the ward environment and thus increasing time for face-to-face patient contact. The programme was introduced in England in 2008, and spread rapidly. By $2009,80 \%$ of English Trusts had signed up ${ }^{9}$; it then spread to a number of other countries. ${ }^{8-10}$

A substantial number of evaluations of TPW:RTC have been published that fall into three broad categories. First, those that describe the programme along with its anticipated benefits. ${ }^{8-11}$ Second, those that describe its adoption, implementation and level of engagement in a particular context or locality. ${ }^{12-16}$ And finally, those that describe reported outcomes from the programme. ${ }^{17-22}$ The majority report benefits of the programme at both staff and patient levels, while others indicate that data support an increase in patient contact time. ${ }^{22-24}$ However, the majority of studies lack rigour with very few robust evaluations. ${ }^{25}$ Recent studies have applied a range of sophisticated methodological approaches. ${ }^{26-28}$ However, robust evidence based on comparator wards is lacking.

In this study we draw on recent methodological advances in complex intervention evaluation design and apply these in a large-scale experimental evaluation of an augmented version of TPW:RTC (TPW:RTCPlus) which included practice development change methods related to leadership, teamwork and caring behaviours. The aim of the study was to assess the impact of TPW:RTC-Plus on patients and nursing staff, specifically, three primary outcomes: experience of nurse communication, nurse shared philosophy of care and emotional exhaustion.

In line with the Medical Research Council's (MRC) guidance on the design and evaluation of complex interventions, ${ }^{29}$ the research team developed a Theory of Change (ToC) that outlined the mechanisms and means by which TPW:RTC-Plus was anticipated to improve patient experience of care.

While the 2011 Rapid Impact Assessment of TPW:RTC ${ }^{30}$ estimated an increase of $42 \%$ direct patient care time, how these data were collected at board level was ambiguous and could not be clearly attributed to the intervention. However, the assessment did predict that there would be improvements in patient experience and a range of safety measures. At the time of the study, there were national programmes being introduced in the participating Board, which focused on improving patient safety. Our ToC (figure 1) therefore focused additionally on the augmented aspects of the intervention and improving patient experience, to contribute to the evidence base.

\section{METHODS}

The aim of the study was to assess the impact of TPW:RTC-Plus on staff and patient primary and secondary outcomes (tables 1 and 2). The trial was necessarily highly pragmatic, thereby ensuring increased likelihood that it could point to real benefits for future roll-out, if they existed.

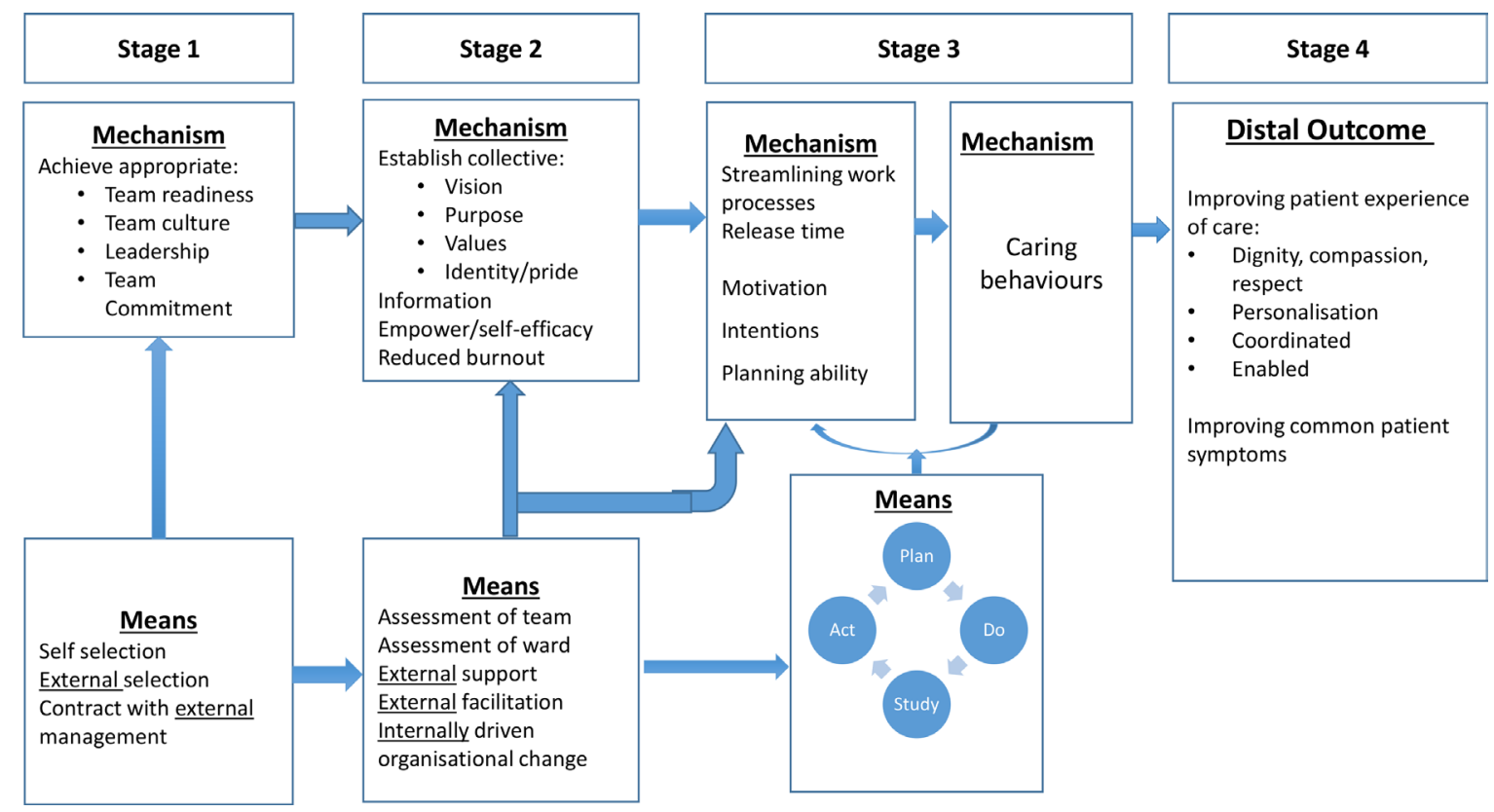

Figure 1 The Productive Ward: Releasing Time to Care (TPW:RTC)-Plus Theory of Change. 
Table 1 Primary outcomes

\begin{tabular}{|c|c|c|c|}
\hline & $\begin{array}{l}\text { Before } \\
\text { Mean (SD) } \\
n\end{array}$ & $\begin{array}{l}\text { After } \\
\text { Mean (SD) } \\
\mathrm{n}\end{array}$ & $\begin{array}{l}\text { Effect size } \\
\text { Adjusted mean } \\
\text { difference } \\
(95 \% \mathrm{Cl})\end{array}$ \\
\hline $\begin{array}{l}\text { HCAHPS nurse } \\
\text { communication }^{35}\end{array}$ & $\begin{array}{l}0.70(0.41) \\
292\end{array}$ & $\begin{array}{l}0.80(0.34) \\
368\end{array}$ & $\begin{array}{l}0.15 \\
(0.05 \text { to } 0.24)\end{array}$ \\
\hline $\begin{array}{l}\text { AHCOP shared } \\
\text { philosophy of } \\
\text { care }^{37}\end{array}$ & $\begin{array}{l}3.84(0.79) \\
184\end{array}$ & $\begin{array}{l}3.86(0.81) \\
163\end{array}$ & $\begin{array}{l}0.42 \\
(0.14 \text { to } 0.70)\end{array}$ \\
\hline $\begin{array}{l}\text { MBI emotional } \\
\text { exhaustion }{ }^{39}\end{array}$ & $\begin{array}{l}21.9(11.0) \\
183\end{array}$ & $\begin{array}{l}21.2(13.8) \\
156\end{array}$ & $\begin{array}{l}-2.33 \\
(-5.92 \text { to } 1.26)\end{array}$ \\
\hline \multicolumn{4}{|c|}{$\begin{array}{l}\text { Results in bold indicate statistically significant improvements. } \\
\text { AHCOP, Acute Hospital Care for Older People; HCAHPS, Hospital Consumer } \\
\text { Assessment of Healthcare Providers and Systems; MBI, Maslach Burnout } \\
\text { Inventory. }\end{array}$} \\
\hline
\end{tabular}

\section{Setting}

Recruitment took place in two acute hospitals in a single Scottish Health Board region serving mixed urban/rural catchment area. The Board was chosen as it was taking part in a national roll-out of TPW:RTC but had not begun implementation.

\section{Study design}

Initial consideration was given to a cluster randomised trial. However, after discussion with the Board it was clear that resources were not available to deliver the intervention to all wards in a fixed time period and there was organisational desire to provide TPW:RTCPlus to all wards. These issues have been cited as legitimate reasons for the adoption of a stepped-wedge trial. $^{3132}$ In a stepped-wedge trial, clusters are usually allocated randomly to prespecified time periods (steps).

The host Board believed that randomisation to steps could severely limit implementation success where factors such as organisational instability influenced wards locally (eg, absence of a clinical leader). Such wards were excluded or deferred until later in the study to optimise their chance of effectively engaging with the intervention. Data from the study were analysed in accordance with a stepped-wedge design. This element of non-randomisation leads to our descriptor of the study as a quasi (non-randomised) or 'naturalistic' stepped-wedge trial. For patients, single measurements were taken from individual participants, but involved different participants at each step of the study. At the patient level, the study is therefore a 'cross-sectional' quasi stepped-wedge trial. ${ }^{33}$ However, we followed nursing staff throughout the study period with new staff permitted to enter the study at any phase of data collection. At the nursing staff level, the study is therefore an 'open cohort' quasi stepped-wedge trial. Recruitment and data collection occurred in six steps, each covering a 4-month period (online supplementary appendix 1). Questionnaires were collected between February 2013 and December 2014.
Sample

Obstetrics, children's and mental health wards, and wards that did not have at least 16 weeks of organisational stability to allow intervention implementation were excluded. This left 15 wards for inclusion. All nursing staff members, at all grades, employed for the length of the step on participating wards were eligible for inclusion. Patients were eligible if they stayed on a participating ward for $\geq 24$ hours during any of the six recruitment periods. Patients transferred to another ward remained eligible. Inpatients $<17$ years and those with an anticipated ward stay of $<24$ hours were excluded. We sought clinical opinion before approaching patients to ensure cognitive competence and readiness of patients to participate. Patients who could not understand English sufficiently to answer the questionnaires were excluded.

\section{Sample size}

The sample size calculation was based on before and after comparisons. The planned sample size of 800 patients across 15 wards for the primary patient outcome (Hospital Consumer Assessment of Healthcare Providers and Systems (HCAHPS) nurse communication) anticipated a 90\% power to detect a difference of 0.025 (or 2.5\%) based on an expected mean of $0.86, \mathrm{SD}$ of 0.08 and intraclass correlation coefficient (ICC) of $0.05 .^{3435}$ For the primary nurse outcomes, the study was designed to have $80 \%$ power to detect standardised effect sizes of 0.22 SD based on a sample size of 394 nurses and ICC of $0.05 .^{36-39}$

\section{Recruitment}

Senior charge nurses (SCN) were informed of the research by the Board Practice Development Team and a member of the research team explained the research to ward staff and provided a copy of the research protocol. Staff members were ensured of data confidentiality and given at least three days to consider participation. There were an average of 31 nursing team members per ward and 15 wards available for the TPW:RTC-Plus interventions. The study aimed to recruit $60 \%$ of eligible staff for each ward.

All eligible patients were given an information leaflet about the study by ward staff. Following a minimum of 24 hours for patients to consider, and in agreement with nursing staff, the research assistant (RA) approached the patient, provided further information regarding the study and sought their consent to participate. After phase 1 (with ethical approval), an additional step was introduced following the initial leaflet. Patients were able to complete a 'permission to contact' form and were contacted after discharge to discuss potential participation. Patients were reassured about the confidentiality of the data they provided. 
Table 2 Secondary patient outcomes

Before

After

Effect estimate

$(95 \% \mathrm{Cl})^{*}$

Time point 1: discharge or ward transfer

HCAHPS $^{35}$

\begin{tabular}{|c|c|c|c|c|}
\hline Nursing servicest & $\mathrm{n}$, mean (SD) & $95,0.63(0.42)$ & $122,0.66(0.37)$ & 0.07 (-0.08 to 0.23$)$ \\
\hline Doctor communication & $\mathrm{n}$, mean (SD) & $302,0.77(0.38)$ & $367,0.77(0.38)$ & $0.09(0.00$ to 0.19$)$ \\
\hline Physical environment & $\mathrm{n}$, mean (SD) & $276,0.49(0.31)$ & $347,0.49(0.31)$ & $0.06(-0.03$ to 0.16$)$ \\
\hline Pain control ${ }^{\star} \dagger$ & $\mathrm{n}$, mean (SD) & $232,0.69(0.40)$ & $244,0.69(0.40)$ & $0.13(0.00$ to 0.26$)$ \\
\hline Communication about medicinest & $\mathrm{n}$, mean (SD) & $191,0.54(0.40)$ & $215,0.54(0.40)$ & $0.07(-0.06$ to 0.21$)$ \\
\hline Discharge information & $\mathrm{n}$, mean (SD) & $233,0.65(0.48)$ & $249,0.65(0.48)$ & $0.09(-0.06$ to 0.24$)$ \\
\hline Fatigue and nausea† & $\mathrm{n}$, mean (SD) & $91,0.79(0.35)$ & $88,0.79(0.35)$ & $-0.12(-0.31$ to 0.06$)$ \\
\hline Overall health & $\mathrm{n}$, mean (SD) & $280,0.45(0.26)$ & $345,0.45(0.26)$ & $-0.02(-0.09$ to 0.05$)$ \\
\hline \multicolumn{5}{|l|}{ PANAS $^{48}$} \\
\hline Positive Affect Scale & $\mathrm{n}$, mean (SD) & $244,26.7(8.2)$ & $263,26.7(8.2)$ & $-0.18(-2.86$ to 2.51$)$ \\
\hline Negative Affect Scale & $\mathrm{n}$, mean (SD) & $251,16.9(6.6)$ & $279,16.9(6.6)$ & $-2.01(-3.84$ to -0.18$)$ \\
\hline \multicolumn{5}{|l|}{$\mathrm{HADS}^{43}$} \\
\hline Anxiety & $\mathrm{n}$, mean (SD) & $258,5.8(4.2)$ & $314,5.8(4.2)$ & $-0.63(-1.77$ to 0.51$)$ \\
\hline Depression & $\mathrm{n}$, mean (SD) & $259,5.0(3.9)$ & $321,5.0(3.9)$ & $-0.49(-1.54$ to 0.55$)$ \\
\hline \multicolumn{5}{|l|}{ EORTC $^{42}$} \\
\hline Pain & $\mathrm{n}$, mean (SD) & $281,46.6(33.1)$ & $323,46.6(33.1)$ & $-7.6(-17.5$ to 2.3$)$ \\
\hline Fatigue & $\mathrm{n}$, mean (SD) & $282,59.2(26.4)$ & $324,59.2(26.4)$ & $-5.6(-13.4$ to 2.2$)$ \\
\hline Nausea/vomiting & $\mathrm{n}$, mean (SD) & $279,15.9(24.1)$ & $321,15.9(24.1)$ & $-1.4(-6.0$ to 8.7$)$ \\
\hline \multicolumn{5}{|l|}{ Ward rating } \\
\hline Confidence in future treatment & $\mathrm{n}$, mean (SD) & $292,8.49(1.9)$ & $357,8.9(1.6)$ & $0.32(-0.12$ to 0.80$)$ \\
\hline Overall ward rating & $\mathrm{n}$, mean (SD) & $293,8.5(1.6)$ & $359,8.9(1.5)$ & $0.46(0.01$ to 0.92$)$ \\
\hline \multicolumn{5}{|c|}{ HCAHPS recommendation to family/friends ${ }^{35}$} \\
\hline Definitely yes & $n / N(\%)$ & 181/294 (61.6) & $255 / 360(70.8)$ & 0.71 (0.40 to 1.26$)$ \\
\hline Probably yes & $\mathrm{n} / \mathrm{N}(\%)$ & $91 / 294(31.0)$ & $87 / 360(24.2)$ & \\
\hline Probably no & $\mathrm{n} / \mathrm{N}(\%)$ & $16 / 294(5.4)$ & $10 / 360(2.8)$ & \\
\hline Defiantly no & $\mathrm{n} / \mathrm{N}(\%)$ & $6 / 294(2.0)$ & $8 / 360(2.2)$ & \\
\hline \multicolumn{5}{|c|}{ Time point 2: 4-6 weeks after discharge/ward transfer } \\
\hline \multicolumn{5}{|l|}{ HCAHPS $^{35}$} \\
\hline Overall health & $\mathrm{n}$, mean (SD) & $130,0.43(0.28)$ & $149,0.40(0.24)$ & $-0.05(-0.14$ to 0.05$)$ \\
\hline \multicolumn{5}{|l|}{ EORTC $^{42}$} \\
\hline Pain & $\mathrm{n}$, mean (SD) & $128,34.9(30.0)$ & $150,37.1(34.9)$ & $-0.5(-12.6$ to 11.7$)$ \\
\hline Fatigue & $\mathrm{n}$, mean (SD) & $129,45.6(29.5)$ & $147,50.3(29.7)$ & $5.9(-5.4$ to 17.3$)$ \\
\hline Nausea/vomiting & $\mathrm{n}$, mean (SD) & $127,8.3(16.5)$ & $149,9.7(20.0)$ & $-0.7(-8.7$ to 7.2$)$ \\
\hline \multicolumn{5}{|l|}{$\begin{array}{l}\text { HCAHPS recommendation to family/ } \\
\text { friends }^{35}\end{array}$} \\
\hline Definitely yes & $n / N(\%)$ & $76 / 131(58.0)$ & $96 / 150(64.0)$ & 0.79 (0.31 to 2.09$)$ \\
\hline Probably yes & $\mathrm{n} / \mathrm{N}(\%)$ & 40/131 (30.5) & $46 / 150(30.5)$ & \\
\hline Probably no & $\mathrm{n} / \mathrm{N}(\%)$ & $12 / 131(9.2)$ & $6 / 150(9.2)$ & \\
\hline Definitely no & $\mathrm{n} / \mathrm{N}(\%)$ & $3 / 131(2.3)$ & $2 / 150(2.3)$ & \\
\hline Patient Enablement Instrument score ${ }^{44}$ & $\mathrm{n}$, mean (SD) & $99,4.05(3.86)$ & $107,4.31(3.75)$ & $0.03(-1.63$ to 1.68$)$ \\
\hline \multicolumn{5}{|l|}{ Ward rating } \\
\hline Overall ward rating & $\mathrm{n}$, mean (SD) & $132,8.1(1.6)$ & $153,8.6(1.5)$ & $0.68(0.49$ to 1.31$)$ \\
\hline Confidence in future treatment & $\mathrm{n}$, mean (SD) & $131,8.4(1.9)$ & $151,8.9(1.7)$ & $0.72(-0.02$ to 1.47$)$ \\
\hline
\end{tabular}

Results in bold indicate statistically significant improvements.

*Effect estimate is the adjusted mean difference, except for recommendation to family/friends where it is an odds ratio.

tThere were screening questions for nursing services, pain control, communication about medicines and fatigue/nausea, so these scrores were only calculated for applicable patients EORTC, European Organization for the Research and Treatment of Cancer; HADS, Hospital Anxiety and Depression Scale; HCAHPS, Hospital Consumer Assessment of Healthcare

Providers and Systems; PANAS, Positive and Negative Affect Schedule.

\section{Control}

Prior to receiving the interventions (control steps), wards were operating under 'normal care' conditions and no other initiatives were introduced or delivered during the study period.

\section{Intervention}

TPW:RTC ${ }^{8}$ shares some principles with Transforming Care at the Bedside in the USA. ${ }^{40}$ It uses methodologies from the business world, including Lean production, ${ }^{41}$ to improve work process and team efficiency 
with the aim of 'releasing time' which would be used to increase caring time spent directly with patients. The team worked through a series of modules facilitated by a member of the Practice Development Team.

While TPW:RTC had the ultimate aim of improving patient care, this aspect is not addressed. There is instead an assumption that nurses will use time gained to increase direct care time. To address this, the Practice Development Team developed the 'Plus' aspect to empower the team to systematically evaluate care standards and experiences and use that in collaborative ways to improve care and care cultures by incorporating into the intervention three measures of quality (staff caring behaviours, patient experience and teamwork). The results from these measures were shared with nursing teams in facilitated sessions as a focus for their improvement efforts. A full description of TPW: RTC-Plus is provided in online supplementary appendix 2.

We therefore hypothesised that TPW:RTC-Plus, with its focus on Lean and a team approach to designing changes based on patient-reported care experiences and peer observations, would result in an increased awareness of the gap between desired care standards and actual care delivered. Crucial to this approach was the facilitated support that was provided to the team to encourage a shared and mutual philosophy of care, improve better team working practices and spend more time with patients.

\section{Blinding}

The nature of the intervention meant that ward staff could not be blinded to what they were receiving. However, given that allocation to the intervention was not at the patient level and that receipt of the intervention was based on time step, it was possible to blind patients.

\section{Outcome measures}

Potential outcome measures were mapped against our ToC model (figure 1). In keeping with the MRC guidance on complex interventions, ${ }^{29}$ several primary outcomes were selected, these covered patient and nurse-level outcomes. The three primary outcome measures chosen had documented validity and reliability. First, the HCAHPS inventory: nurse communication subscale, ${ }^{35}$ completed by patients. Second, the Acute Hospital Care for Older People (AHCOP) toolkit; a measure of 'shared philosophy of care', completed by nursing staff. ${ }^{37}$ Third, the Maslach Burnout Inventory (MBI) Emotional Exhaustion (EE) component scale for nursing staff. ${ }^{39}$ The full range of secondary outcome measures is found in online supplementary appendix 3 .

The distal patient primary outcome, nurse communication, derived from HCAHPS, was developed in the USA as a patient-reported questionnaire to benchmark patient experience of hospital care quality. It was important that the measure of care reflected behaviours experienced at ward level, therefore the measure was adapted. The nurse communication subscale consisted of four summed questions relating to: courtesy and respect; nurses listening carefully; nurses explaining things in a way which the patient could understand; and responses to call buttons. Possible responses were: Never, Sometimes, Usually or Always, scored 0-3 respectively. Other subscales were used as secondary outcomes (your care from your nurses; your care from your doctors; the ward environment; your experiences in this ward; overall rating of the ward; general health; care for pain; care for fatigue and nausea symptoms (adapted)) (online supplementary appendix 3).

Beyond the ToC, the study also examined whether the intervention might reduce symptoms. Secondary outcomes included patients' experience of pain, fatigue and nausea symptoms using the European Organization for the Research and Treatment of Cancer Quality of Life Questionnaire (EORTC QLQ-C30) measures. ${ }^{42}$ They were also asked about anxiety and depression using the Hospital and Anxiety Depression Scale. ${ }^{43}$ The research team was also interested whether the intervention had the potential to improve postdischarge self-care measured by the Patient Enablement Instrument ${ }^{44}$ and follow-up symptom questions. The potential of the intervention to impact on clinical outcomes was assessed via an examination of hospital records to identify frequency of emergency admissions for same diagnosis with 6 months of discharge.

A staff primary outcome, shared philosophy of care, was derived from the AHCOP, a collection of patient relative/carer, SCN and nursing team questionnaires. The nursing team scale consists of a number of subscales. The subscale 'shared philosophy of care' was seen as a potential proxy measure for the stage 2 mechanisms of collective vision, purpose, value and identity in our ToC model. The subscale consists of five summed questions relating to: sharing an explicit philosophy of care; valuing psychological aspects of care; communicating the philosophy of care to new staff; involving patients and carers; and valuing relational rather than procedural work. Possible responses, on a 5-point Likert scale, ranged from strongly disagree to strongly agree, scored 1-5 respectively. Other subscales were used as secondary outcomes: having resources; supporting each other; feeling safe; improving practice; having a say; developing our skills; too much to do; multidisciplinary team working; leading by example; and support from the top (online supplementary appendix 3).

The third primary outcome was based on the premise that increased empowerment and efficiency could help reduce the stress experienced by nursing staff. To measure this, the MBI (EE subscale) (Human Services Survey Form) was used (22 summed questions). ${ }^{39}$ This was rated on a 7-point frequency scale from never to every day. 
Other secondary outcomes included questions at the SCN level. These included two subscales from the AHCOP: meeting patients' needs; looking to improve. Scoring was similar to the nurse questions. Nurses and SCNs were also asked an adapted version of Swanson's Caring Professional Scale. ${ }^{45}$ This includes two subscales of attributes of caring behaviours: compassionate healer, competent practitioner. They were also asked an adapted global care question, as a correlate of the net promoter question asked of patients, ${ }^{35}$ 'If a relative or friend were to become a patient in this ward, how confident would you be that they would get the care they needed and deserved?' (scored 0-100).

\section{Data collection}

Questionnaire data were collected during six prespecified fortnightly periods, beginning with one at baseline (pre-intervention), when all wards were in the control arm of the study, then during four subsequent fortnights for each phase of the quasi stepped wedge and during a final fortnight in the follow-up post-intervention phase. We employed three RAs to ensure ward staff were not involved in the recruitment of patients or collecting data from patients. Questionnaires were precoded with a unique participant ID (hospital ward/identifier/check code).

Patients were asked to complete a paper Ward questionnaire at/after discharge/transfer (or at the end of the data collection phase, whichever came first). Patients discharged directly home were asked to complete a follow-up, Home questionnaire 4-6 weeks later. At both stages, RAs offered to provide assistance to patients to mitigate potential literacy or burden issues. The Home questionnaire could be completed by post, telephone or online.

Consenting SCNs completed a questionnaire for each participating ward. This was repeated at each time phase (six) of the study. All consenting nursing team staff members were asked to complete a questionnaire at each time phase (six). Contributors were entered into a prize draw with one winner per phase of collection winning a $£ 50$ voucher, and a $£ 5$ voucher for each member of their team who returned a questionnaire.

\section{Data management}

Data were digitised (optical character recognition), pseudonymised and stored by the Health Informatics Centre (HIC) at University of Dundee. The Community Health Index number was used to pseudonymise study data sets, with patient consent, to link hospital records. Identifiable data were retained on National Health Service (NHS) networks by HIC. Data released by HIC to the research team for analysis were anonymised and held securely on Glasgow Caledonian University computers.
Analysis

Analysis was conducted on an 'intention to treat' basis, operationalised within a stepped-wedge design as analysed according to the allocated cross-over time, irrespective of whether that was achieved. ${ }^{31} 33$ Analysis of the primary outcomes estimated the effect of the interventions from the mean differences (and 95\% CIs) before and after the intervention using a generalised linear multilevel mixed model, by regressing the outcome variable on an indicator variable (ie, before or after intervention received) adjusting for baseline covariates and clustering at ward and hospital levels. Models were adjusted for age, gender, deprivation, religion, ethnicity, education, employment and household status (for patient outcomes), and age, gender, years of experience, contracted weekly hours and grade (for all nurse outcomes) with the addition of qualification for SCN outcomes. Recruitment phases were fitted as fixed effects. Significance was set at the $5 \%$ level. All secondary outcomes were analysed in a manner similar to the analysis of the primary outcome, but using generalised linear multilevel mixed models appropriate for the type of data including ordered logit regression for ordinal outcomes. Statistical analysis was conducted using Stata version 13 (StataCorp LP, TX, USA). ${ }^{46}$

\section{Missing data}

Imputation of questionnaire responses was undertaken at item level according to the rules of the specific instrument. Where the instrument had no specific requirements relating to missing data, item-level data which were missing were replaced using person mean substitution (otherwise known as ipsative mean imputation or pro-rating) provided that no more than half of the items in the scale were missing for the individual respondent. Otherwise, the scale value remained missing.

\section{RESULTS}

\section{Overview}

We successfully recruited 691 patients, 177 nurses and 14 SCNs. Consolidated Standards of Reporting Trials diagrams for both patients and nurses are shown in figure 2. Our sample was almost exclusively white, broadly reflecting the demographics of the catchment area. Comparison with national figures indicates that this sample was representative in terms of age and gender. They were slightly more advantaged relative to the national figure. ${ }^{47}$ See online supplementary appendix 4 for patient demographics.

\section{Primary outcomes}

Statistically significant improvements were seen for patient experience measured by the HCAHPS subscale for nurse communication (mean difference $=0.15$, 95\% CI 0.05 to 0.24$).{ }^{35}$ In addition, the nurse reported AHCOP shared philosophy of care demonstrated a 

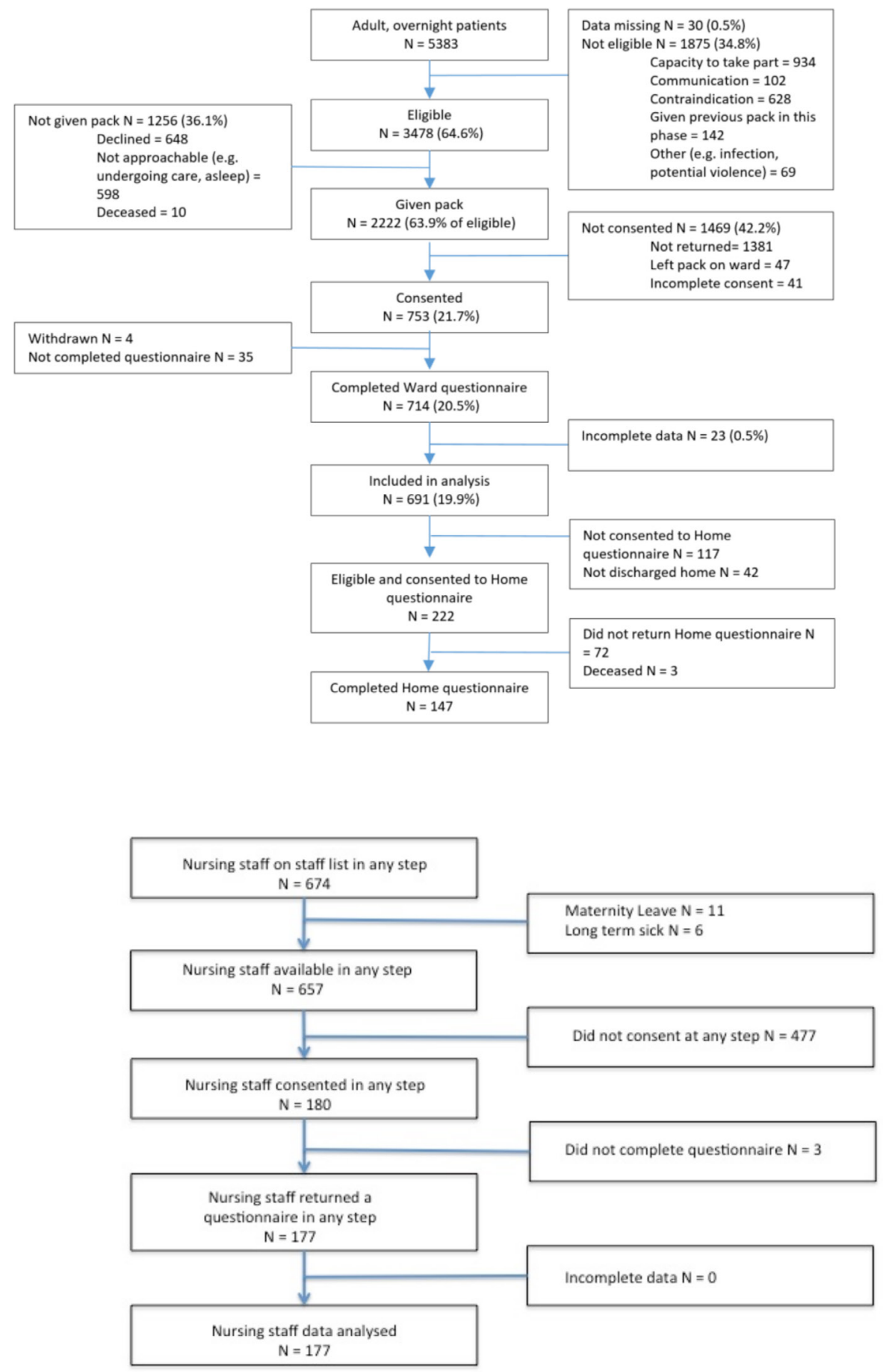

Figure 2 Patient and nurse recruitment.

statistically significant improvement (mean difference $=0.42,95 \%$ CI 0.14 to 0.70$).{ }^{37}$ No statistically significant improvement was seen for the MBI EE scores reported by nurses ${ }^{39}$ (table 1 ).

\section{Secondary outcomes: patients}

Patients were more likely to rate the ward more highly following TPW:RTC-Plus intervention, both at discharge from the ward (Ward questionnaire mean difference; 0.46 (95\% CI 0.01 to 0.92$)$ ) and at follow-up at home (Home questionnaire effect estimate; 0.68 (95\% CI 0.49 to 1.31$)$ ).

Patient improvements in reports of HCAHPS doctor communication (effect estimate; 0.09 (95\% CI 0.00 to $0.19)$ ) and HCAHPS pain control (mean difference; 0.13 (95\% CI 0.00 to 0.26)) following TPW:RTCPlus approached statistical significance. ${ }^{35}$ No other effects were found in the remainder of the HCAHPS measures, or in EORTC, Positive and Negative Affect Schedule (PANAS) or Hospital Anxiety and Depression Scale measures ${ }^{42} 4348$ (table 2). 
A simple bivariate analysis examining the effect of the intervention on the incidence of emergency admission for the same diagnosis within 6 months of discharge found no significant difference (Pearson $\chi^{2}=1.68$; $\mathrm{p}=0.194$ ). After multivariate analysis (random effects model) accounting for sex, age, Scottish index of multiple deprivation (SIMD), qualifications, employment and household status, there was still no significant intervention effect (adjusted OR 1.18; 95\% CI 0.65 to 2.13 ).

\section{Secondary outcomes: nurses and SCNs}

A series of statistically significant improvements in nursing team outcomes was apparent. AHCOP 'supporting each other' (mean difference $=0.45$, $95 \%$ CI 0.15 to 0.74 ), AHCOP 'feeling safe' (mean difference $=0.43,95 \% \mathrm{CI} 0.05$ to 0.81 ), AHCOP 'improving practice' (mean difference $=0.37,95 \% \mathrm{CI}$ 0.05 to 0.69 ) and AHCOP 'leading by example' (mean difference $=0.33,95 \% \mathrm{CI} 0.01$ to 0.66 ) all showed positive increases following the intervention, indicating an improvement in nursing team climate. ${ }^{37}$ TPW:RTC-Plus was also associated with a positive effect on Positive Affect (mean difference=2.83, 95\% CI 0.66 to 5.00$).{ }^{48}$ TPW:RTC-Plus had significant, though modest effects on nursing team culture and nursing resilience. ${ }^{37}$

There were no significant changes in SCN reports relating to AHCOP 'meeting the needs of patients', AHCOP 'looking to improve'37 (table 3). SCN confidence that patients and families receive appropriate treatment was high at outset and improved marginally, but not significantly. The CIs for the effect sizes were wide, suggesting heterogeneity in intervention effect at the ward level. There was no effect of TPW:RTCPlus on either subscale from the Caring Professional Scale. ${ }^{45}$

Table 3 Secondary nursing outcomes

\begin{tabular}{|c|c|c|c|c|}
\hline Nursing staff outcomes & & Before & After & $\begin{array}{l}\text { Mean difference } \\
(95 \% \mathrm{Cl})\end{array}$ \\
\hline \multicolumn{5}{|l|}{$\mathrm{MBI}^{39}$} \\
\hline Depersonalisation & $\mathrm{n}$, mean $(\mathrm{SD})$ & $183,8.4(4.5)$ & $154,9.4(5.5)$ & $-0.62(-2.54$ to 1.31$)$ \\
\hline Personal achievement & $\mathrm{n}$, mean (SD) & $178,33.0(7.0)$ & $155,32.1(7.5)$ & $0.82(-1.65$ to 3.29$)$ \\
\hline \multicolumn{5}{|l|}{$\mathrm{AHCOP}^{37}$} \\
\hline \multicolumn{5}{|l|}{ Nursing team climate } \\
\hline Having resources & $\mathrm{n}$, mean $(\mathrm{SD})$ & $187,2.9(1.0)$ & $165,3.0(1.0)$ & $0.24(-0.10$ to 0.59$)$ \\
\hline Supporting each other & $\mathrm{n}$, mean (SD) & $188,3.3(0.8)$ & $164,3.4(0.9)$ & $0.45(0.15$ to 0.74$)$ \\
\hline Feeling safe & $\mathrm{n}$, mean $(\mathrm{SD})$ & $188,3.1(1.0)$ & $165,3.1(1.0)$ & $0.43(0.05$ to 0.81$)$ \\
\hline Improving practice & $\mathrm{n}$, mean $(\mathrm{SD})$ & $183,3.3(0.9)$ & $162,3.3(0.9)$ & 0.37 (0.05 to 0.69$)$ \\
\hline Having a say & $\mathrm{n}$, mean $(\mathrm{SD})$ & $186,3.2(0.9)$ & $165,3.0(1.0)$ & $0.09(-0.25$ to 0.44$)$ \\
\hline Developing our skills & $\mathrm{n}$, mean $(\mathrm{SD})$ & $185,2.8(1.2)$ & $162,2.9(1.1)$ & $0.09(-0.35$ to 0.52$)$ \\
\hline Too much to do & $\mathrm{n}$, mean $(\mathrm{SD})$ & $185,3.3(1.0)$ & $162,3.3(1.1)$ & $0.01(-0.43$ to 0.45$)$ \\
\hline Multidisciplinary team working & $\mathrm{n}$, mean $(\mathrm{SD})$ & $184,3.9(0.9)$ & $164,4.0(0.9)$ & $0.13(-0.17$ to 0.43$)$ \\
\hline Leading by example & $\mathrm{n}$, mean $(\mathrm{SD})$ & $185,3.6(1.0)$ & $161,3.6(1.1)$ & $0.33(0.01$ to 0.66$)$ \\
\hline Support from the top & $\mathrm{n}$, mean $(\mathrm{SD})$ & $183,2.9(0.8)$ & $160,3.0(0.8)$ & $0.19(-0.11$ to 0.49$)$ \\
\hline Quality of person-centred care & $\mathrm{n}$, mean $(\mathrm{SD})$ & $184,4.2(0.7)$ & $164,4.1(0.8)$ & $0.22(-0.06$ to 0.51$)$ \\
\hline \multicolumn{5}{|l|}{ PANAS $^{48}$} \\
\hline Positive Affect Scale & $\mathrm{n}$, mean $(\mathrm{SD})$ & $163,37.5(7.1)$ & $149,37.9(7.5)$ & $2.83(0.66$ to 5.00$)$ \\
\hline Negative Affect Scale & $\mathrm{n}$, mean $(\mathrm{SD})$ & $168,15.8(5.3)$ & $155,17.1(8.0)$ & $0.48(-1.55$ to 2.50$)$ \\
\hline Confidence in necessary treatment & $\mathrm{n}$, mean $(\mathrm{SD})$ & $184,80.5(17.9)$ & $153,77.8(21.9)$ & $1.31(-4.92$ to 7.54$)$ \\
\hline \multicolumn{5}{|l|}{ Caring Professional Scale ${ }^{45}$} \\
\hline Compassionate healer & $\mathrm{n}$, mean $(\mathrm{SD})$ & $180,32.0(5.0)$ & $157,32.1(5.5)$ & $0.21(-1.78$ to 2.19$)$ \\
\hline Competent practitioner & $\mathrm{n}$, mean $(\mathrm{SD})$ & $184,28.2(4.1)$ & $159,28.2(4.7)$ & $0.64(-0.93$ to 2.21$)$ \\
\hline \multicolumn{5}{|l|}{ Senior charge nurse outcomes } \\
\hline \multicolumn{5}{|l|}{$\mathrm{AHCOP}^{37}$} \\
\hline Meeting needs of patients & $\mathrm{n}$, mean $(\mathrm{SD})$ & $21,3.9(0.8)$ & $14,4.0(0.6)$ & $-0.10(-0.51$ to 0.31$)$ \\
\hline Looking to improve & $\mathrm{n}$, mean $(\mathrm{SD})$ & $21,3.5(0.5)$ & $14,3.5(0.4)$ & $0.33(-0.09$ to 0.75$)$ \\
\hline Confidence in necessary treatment & $\mathrm{n}$, mean $(\mathrm{SD})$ & $20,91.7(9.8)$ & $13,92.9(7.1)$ & $4.33(-2.31$ to 10.98$)$ \\
\hline \multicolumn{5}{|l|}{ Caring Professional Scale ${ }^{45}$} \\
\hline Compassionate healer & $\mathrm{n}$, mean $(\mathrm{SD})$ & $28,33.7(4.0)$ & $29,34.1(3.7)$ & $0.94(-1.05$ to 2.93$)$ \\
\hline Competent practitioner & $\mathrm{n}$, mean $(\mathrm{SD})$ & $28,29.0(2.8)$ & $29,29.4(3.2)$ & $(-0.68$ to 2.53$)$ \\
\hline
\end{tabular}

Results in bold indicate statistically significant improvements.

AHCOP, Acute Hospital Care for Older People; MBI, Maslach Burnout Inventory; PANAS, Positive and Negative Affect Schedule. 


\section{DISCUSSION}

TPW:RTC-Plus was successful in improving dimensions of patient and nurse experience and evaluations of the quality of care received. We found statistically significant improvements in two out of three primary outcomes: patients' experiences of nurse communication and nurses' shared philosophy of care. A lack of evidence of improvement in nurse-reported emotional exhaustion should be further explored, but is consistent with a lack of change in reported Negative Affect (PANAS); the ToC should be revisited. There were also significant improvements in secondary outcomes: patients' overall rating of ward quality; nurses' positive affect and team climate.

\section{Strengths and limitations}

Addressing criticism of other studies we employed an experimental design, with comparator wards located within the same health board, enabling wider hospital factors that may have contributed to changes to be accounted for. Validated tools were used to test the underlying theory embedded within the intervention. We included a key intended outcome, patient experience. ${ }^{40}$ Patients were blind to the intervention being delivered and provided outcome data at both discharge and follow-up.

We acknowledge the relatively moderate rate of patient recruitment and our inability to blind staff to the intervention, which may produce a Hawthorne effect. ${ }^{49}$ Additionally, our inability to randomise wards to particular steps means secular trends may have contributed to an effect. ${ }^{50}$ However, we can confidently attribute outcomes to the intervention as a parallel stepped-wedge trial (reported elsewhere) for a different intervention, in the same locality, found no significant change.

It can be said that if time is released for direct care, the explicit outcome for TPW:RTC, it would be methodologically challenging to attribute how any time released was spent. For example, time released (at our point of measurement) may have partially been allocated to further improvement.

\section{Comparison with previous literature}

Other studies have suggested that TPW:RTC increased direct care time with patients, ${ }^{22-24}$; however, we believe ours to be the first to show an impact on patient experience itself within a robust design. Furthermore, other elements were approaching statistical significance (eg, doctor communication, physical environment, communication about medicines and discharge). Significant complaints and determinants of patient dissatisfaction relate to poor communication and interpersonal skills, ${ }^{51} 52$ suggesting communication is central to improving patient ratings of quality of care. Our findings indicate that TPW:RTC-Plus has potential to reduce the growing complaint figures within the NHS. ${ }^{53}$ Evaluating complaints as part of this study was not possible due to lack of ward-level attribution. The question as to whether the TPW:RTC can improve wider elements of patient experience or clinical outcomes remains unclear.

Our finding of a change in primary outcome: shared philosophy of care, and secondary outcomes: supporting each other; feeling safe; improving practice and staff positive aspect may overlap White and Waldron's $^{54}$ review of 96 papers examining TPW: RTC. These suggestd potential impacts in nine areas: empowerment, leadership, engagement, stress and resilience, teamwork, morale, role enhancement, sociocultural impact and staff satisfaction. ${ }^{54}$ This may go some way to explaining findings elsewhere that TPW:RTC has the capacity to improve 'work engagement', ${ }^{3755}$ defined as 'a positive fulfilling work related state of mind characterised by vigour, dedication and absorption'. ${ }^{56}$

\section{Implications for practice and future research}

Providing robust evidence for the impact of complex quality initiatives being delivered in complex, everchanging settings is not straightforward. Our evaluation focused on an augmented version of TPW:RTC and we cannot disentangle the impact of the additional element (the Plus) or how the time released is used to benefit patients. The intervention was nonetheless designed on evidence supporting practice development methodology, which empowers staff transformation care quality. We would suggest incorporating it within wider roll-outs.

Future research could focus on four key areas: improvements to TPW:RTC-Plus, effective implementation, sustainability and understanding which caring behaviours are impacting on patient experience. While TPW:RTC-Plus appears to produce a number of welcome impacts, the mechanism(s) by which these are achieved are not clear. Finally, the 'Theseus Paradox' applies to this context. A single implementation of TPW:RTC-Plus on a ward is unlikely to produce sustainable change. There is a question as to whether an object that has had all of its components replaced over time retains its original characteristics or essentially becomes a new object; this may apply to healthcare interventions that shift over time. ${ }^{57}$ In this case, wards with frequent staff turnover may essentially become a different ward over time. Future work could develop indicators to suggest further 'top-ups' where appropriate.

\footnotetext{
Author affiliations

${ }^{1}$ School of Health and Social Care, Edinburgh Napier University, Edinburgh, UK

${ }^{2}$ Faculty of Health Sciences and Sport, University of Stirling, Stirling, UK

${ }^{3}$ Division of Nursing, Queen Margaret University Edinburgh, Musselburgh, UK

${ }^{4}$ Nursing, Midwifery and Allied Health Professions Research Unit, University of Stirling, Stirling, UK

${ }^{5}$ Nursing, Midwifery and Allied Health Professions Research Unit, Glasgow Caledonian University, Glasgow, UK

${ }^{6}$ School of Nursing and Health Sciences, University of Dundee, Dundee, UK
} 
Twitter Edward A S Duncan @easduncan and Andrew Elders @andyelders1

Acknowledgements The authors thank NHS Tayside for their support for this study and the staff for their time and participation.

Contributors BW led the design and directed the study, developed the Theory of Change logic model and contributed to analysis and interpretation of data. $\mathrm{CH}$ contributed to the design of the study, managed study implementation and acquisition of data and contributed to interpretation of data. $\mathrm{AE}$ contributed to the study design, and led the statistical analysis and interpretation of data. DB, EASD, MCJ, MM, JER, JC and HS contributed expertise to the study design, data analysis and interpretation. All authors contributed to drafting and revising the article, and final approval of the version for submission.

Funding This article reports independent research funded by the Chief Nurses Directorate, Scottish Government.

Disclaimer The views are those of the authors and not necessarily those of the Scottish Government.

\section{Competing interests None declared.}

Patient consent for publication Not required.

Ethics approval Ethical approval was provided by the East of Scotland Research Ethics Committee (IRAS ID 112898 REC reference 12/ES/0091).

Provenance and peer review Not commissioned; externally peer reviewed.

Data availability statement Data are available upon reasonable request. All data relevant to the study are included in the article or uploaded as supplementary information. Anonymised data are held securely on University of Dundee computers (Dundee Epidemiology and Biostatistics Unit, DEBU). Data are available upon request but must comply with information governance requirements.

Open access This is an open access article distributed in accordance with the Creative Commons Attribution Non Commercial (CC BY-NC 4.0) license, which permits others to distribute, remix, adapt, build upon this work noncommercially, and license their derivative works on different terms, provided the original work is properly cited, appropriate credit is given, any changes made indicated, and the use is noncommercial. See: http://creativecommons.org/licenses/by-nc/4. $0 /$.

\section{ORCID iDs}

Andrew Elders http://orcid.org/0000-0003-4172-4702

Heather Strachan http://orcid.org/0000-0003-2232-5634

\section{REFERENCES}

1 Donabedian A. Evaluating the quality of medical care. 1966. Milbank Q 2005;83:691-729.

2 Campbell SM, Roland MO, Buetow SA. Defining quality of care. Soc Sci Med 2000;51:1611-25.

3 Institute of Medicine Committee on Quality of Health Care in A. Crossing the quality chasm: a new health system for the 21st century. crossing the quality chasm: a new health system for the 21st century. Washington (DC: National Academies Press (US), 2001.

4 Pannick S, Beveridge I, Wachter RM, et al. Improving the quality and safety of care on the medical ward: a review and synthesis of the evidence base. Eur J Intern Med 2014;25:874-87.

5 Pannick S, Wachter RM, Vincent C, et al. Rethinking medical ward quality. BMJ 2016;355:i5417-i.

6 Wells M, Williams B, Treweek S, et al. Intervention description is not enough: evidence from an in-depth multiple case study on the untold role and impact of context in randomised controlled trials of seven complex interventions. Trials 2012;13:95.

7 Bugge C, Williams B, Hagen S, et al. A process for decisionmaking after pilot and feasibility trials (ADEPT): development following a feasibility study of a complex intervention for pelvic organ prolapse. Trials 2013;14:353.

8 NHS Institute for Innovation and Improvement. The productive series: NHS UK; 2017, 2017. Available: https:// www.england.nhs.uk/improvement-hub/publication/theproductive-series/

9 Blakemore S. How productive wards can improve patient care. Nurs Manag 2009;16:14-18.

10 Avis K. Releasing time to Care $\odot$ in Saskatchewan: promising signs for engaging clinicians (summary report). Canada: Saskatoon: Health Quality Council, 2009.

11 Bloodworth K, Ward P. Productive ward. 1: implementing the initiative across a large university teaching hospital. Nurs Times 2009;105:22-5.

12 Davis J, Adams J. The 'Releasing Time to Care--the Productive Ward' programme: participants' perspectives. J Nurs Manag 2012;20:354-60.

13 Hamilton J, Verrall T, Maben J, et al. One size does not fit all: a qualitative content analysis of the importance of existing quality improvement capacity in the implementation of releasing time to care: the productive Ward ${ }^{\mathrm{TM}}$ in Saskatchewan, Canada. BMC Health Serv Res 2014;14:642.

14 Morrow E, Robert G, Maben J. Exploring the nature and impact of leadership on the local implementation of the productive ward releasing time to care.J Health Organ Manag 2014;28:154-76.

15 Morrow E, Robert G, Maben J, et al. Implementing largescale quality improvement: lessons from the productive ward: releasing time to care. Int J Health Care Qual Assur 2012;25:237-53.

16 Smith J, Rudd C. Implementing the productive ward management programme. Nurs Stand 2010;24:45-8.

17 Wright S, McSherry W. Evaluating the productive ward at an acute NHS trust: experiences and implications of releasing time to care. J Clin Nurs 2014;23:1866-76.

18 Wright S, McSherry W. A systematic literature review of releasing time to care: the productive ward. J Clin Nurs 2013;22:1361-71.

19 Lennard C. Productive ward initiative promotes better communication between mental health teams and ensures timely discharge for patients. J Psychiatr Ment Health Nurs 2014;21:93-6.

20 Gribben BMT, Slater P. Productive Ward- Releasing Time to Care. Evaluation Report November 2008 to March 2009. Belfast Health \& Social Care Trust 2009.

21 Brunoro-Kadash C, Kadash N. Time to care: a patientcentered quality improvement strategy. Leadersh Health Serv 2013;26:220-31.

22 Gribben B, McCance T, Slater P. Productive Ward- Releasing Time to Care. Evaluation Report November 2008 to March 2009. Belfast: Belfast Health \& Social Care Trust. Belfast Health \& Social Care Trust 2009.

23 Cook F, Main J. Releasing time to care: making our priorities possible. Edinburgh.: Healthcare Improvement Scotland \& NHS Education for Scotland, 2013.

24 Foster S, Gordon P, McSherry W. Rolling out productive ward Foundation modules across a hospital trust. Nurs Times 2009;105:28-30. 
25 White M. How effective is productive ward? Nursing Times 2015;111:22-5.

26 White M, Butterworth T, Wells JS. Healthcare Quality Improvement and 'work engagement'; concluding results from a national, longitudinal, cross-sectional study of the 'Productive Ward-Releasing Time to Care' Programme. BMC Health Serv Res 2017;17:510.

27 White M, Butterworth T, Wells JSG. Reported implementation lessons from a national quality improvement initiative; productive ward: releasing time to Care ${ }^{\mathrm{TM}}$. A qualitative, wardbased team perspective. J Nurs Manag 2017;25:519-30.

28 Van Bogaert P, Van heusden D, Somers A, et al. The productive ward program ${ }^{\mathrm{TM}}$ : a longitudinal multilevel study of nurse perceived practice environment, burnout, and nurse-reported quality of care and job outcomes. J Nurs Adm 2014;44:452-61.

29 Craig P, Dieppe P, Macintyre S, et al. Developing and evaluating complex interventions: the new medical Research Council guidance. BMJ 2008;337:a1655.

30 Improvement NIfI. Rapid impact assessment of the productive ward: releasing time to care. NHS Institute for Innovation and Improvement, 2011.

31 Hemming K, Haines TP, Chilton PJ, et al. The stepped wedge cluster randomised trial: rationale, design, analysis, and reporting. BMJ 2015;350:h391.

32 Brown CA, Lilford RJ. The stepped wedge trial design: a systematic review. BMC Med Res Methodol 2006;6:54.

33 Hemming K, Lilford R, Girling AJ. Stepped-wedge cluster randomised controlled trials: a generic framework including parallel and multiple-level designs. Stat Med 2015;34:181-96.

34 Elliott MN, Lehrman WG, Beckett MK, et al. Gender differences in patients' perceptions of inpatient care. Health Serv Res 2012;47:1482-501.

35 AHRQ. Hospital consumer assessment of healthcare providers and systems. Rockville, MD. survey vs2.0 instructions: health services Advisory group, 2012. Available: http://www.hcahps. org/

36 Edmonds C, Lockwood GM, Bezjak A, et al. Alleviating emotional exhaustion in oncology nurses: an evaluation of Wellspring's "Care for the Professional Caregiver Program". J Cancer Educ 2012;27:27-36.

37 Patterson MMG. From metrics to meaning: culture change and quality of acute hospital care for older people. NIHR SDO. Report No.: SDO project (08/1501/93), 2011.

38 Hussey MA, Hughes JP. Design and analysis of stepped wedge cluster randomized trials. Contemp Clin Trials 2007;28:182-91.

39 Maslach CJS, Leiter M. Maslach burnout inventory manual ED3. Mindgarden.com 1996.

40 Rutherford P, Lee B, Greiner A. Transforming care at the bedside. Institute for healthcare improvement 2004.

41 Powell AE, Rushmeer R, Davies $\mathrm{H}$, et al. A systematic narrative review of quality improvement models in health care: NHS quality improvement Scotland Edinburgh 2009.
42 Aaronson NK, Ahmedzai S, Bergman B, et al. The European organization for research and treatment of cancer QLQ-C30: a quality-of-life instrument for use in international clinical trials in oncology. J Natl Cancer Inst 1993;85:365-76.

43 Zigmond AS, Snaith RP. The hospital anxiety and depression scale. Acta Psychiatr Scand 1983;67:361-70.

44 Howie JG, Heaney DJ, Maxwell M, et al. A comparison of a patient enablement instrument (PEI) against two established satisfaction scales as an outcome measure of primary care consultations. Fam Pract 1998;15:165-71.

45 Swanson KM. Predicting depressive symptoms after miscarriage: a path analysis based on the Lazarus paradigm. $J$ Womens Health Gend Based Med 2000;9:191-206.

46 Stata Statistical Software. Release 13. 13 ED. College Station, TX: StataCorp LP, 2013.

47 Scottish Government. Inpatient experience survey 2018 national results, 2018. Available: https://www.gov.scot/binaries/ content/documents/govscot/publications/statistics/2018/08/ inpatient-experience-survey-2018-national-results/documents/ 00539637-pdf/00539637-pdf/govscot\%3Adocument/ 00539637.pdf

48 Watson D, Clark LA, Tellegen A. Development and validation of brief measures of positive and negative affect: the PANAS scales. J Pers Soc Psychol 1988;54:1063-70.

49 McCambridge J, Witton J, Elbourne DR. Systematic review of the Hawthorne effect: new concepts are needed to study research participation effects. J Clin Epidemiol 2014;67:267-77.

50 Hargreaves JR, Prost A, Fielding KL, et al. How important is randomisation in a stepped wedge trial? Trials 2015;16:359.

51 Anderson K, Allan D, Finucane P. A 30-month study of patient complaints at a major Australian hospital. J Qual Clin Pract 2001;21:109-11.

52 Vincent C, Young M, Phillips A. Why do people Sue doctors? A study of patients and relatives taking legal action. Lancet 1994;343:1609-13.

53 Hickson GB, Jenkins AD. Identifying and addressing communication failures as a means of reducing unnecessary malpractice claims. N C Med J 2007;68:362-4.

54 White M, Waldron M. Effects and impacts of productive ward from a nursing perspective. Br J Nurs 2014;23:419-26.

55 White M, Wells JS, Butterworth T. The Productive Ward: releasing Time to Care $\left({ }^{\mathrm{TM}}\right)$---what we can learn from the literature for implementation. J Nurs Manag 2014;22:914-23.

56 Schaufeli WB, Salanova M, González-romá V, et al. The measurement of engagement and burnout: a two sample confirmatory factor analytic approach.J Happiness Stud 2002;3:71-92.

57 Ansari I, Futane S, Ansari A. Endoscope-assisted, minimally invasive evacuation of sub-acute/chronic epidural hematoma: novelty or paradox of Theseus? Acta Neurochir 2016;158:1473-8. 